\title{
LIBERTAD DE INFORMACIÓN, REDES MEDIÁTICAS Y CONTROL ESTATAL. ESTUDIO DE CASO
}

\author{
María Luisa Soriano González ${ }^{1}$
}

\begin{abstract}
RESUMEN: El objetivo del trabajo es precisar el valor mediático de la revolución zapatista de las comunidades indígenas de Chiapas en el proceso de conquista de su autonomía política asentada sobre las bases de una democracia asamblearia contrapuesta a la democracia formal y representativa del Estado mexicano. De ahí que el trabajo responda a la construcción mediática de la democracia del zapatismo. Apartados del trabajo son: a) la descripción de los caracteres de la citada revolución insistiendo en su valor mediático, b) la explicación de los espacios mediáticos que cubre la revolución, c) las causas y los factores que explican el éxito mediático de la revolución, d) la función mediática que desarrolla el subcomandante Marcos, portavoz y jefe militar de la revolución, y e) la estrategia de la indefinición política del zapatismo, con la finalidad de allegar a sus filas al mayor número de propagadores y colaboradores en el éxito de los objetivos revolucionarios. La conclusión principal es que contribuyeron al éxito de la revolución la indefinición ideológica del zapatismo y la función extraordinaria mediática del subcomandante Marcos, jefe militar de la revolución.
\end{abstract}

PALABRAS CLAVE: libertad de información, zapatismo, revolución mediática, internet, luchas indígenas

\section{INTRODUCCIÓN.}

Me ha parecido oportuno comenzar mi trabajo reseñando los hechos más destacados y los caracteres de la revolución indígena zapatista de Chiapas, porque en el entramado de estos caracteres el lector puede apreciar el valor mediático de esta revolución, denominada por muchos tratadistas como la primera revolución mediática en la que internet desarrolló un gran papel. Tras una breve narración de los hitos más importantes de la revolución y la descripción de sus caracteres (segundo y tercer epígrafe) se pasa a la explicación de los

\footnotetext{
${ }^{1}$ Profesora contratada doctora en la Universidad Pablo de Olavide de Sevilla en el Departamento de Derecho Público, Área Filosofía del Derecho. Licenciada en Filosofía por la Universidad de Sevilla y doctora europea en Pensamiento político, democracia y ciudadanía con Sobresaliente cum laude por unanimidad por la Universidad Pablo de Olavide, es autora de dos libros y una veintena de artículos de fondo publicados en revistas científi cas, siendo su campo especial de investigación la fi losofía política, los derechos de los pueblos indígenas y los derechos humanos. Es Miembro del Grupo de Investigación PAIDI SEJ-277, Plan Andaluz de Investigación de la Junta de Andalucía, y del Laboratorio de Ideas y Prácticas Políticas, Centro ofi cial de Investigación de la Universidad Pablo de Olavide. Ha participado en cuatro proyectos de investigación I+D de excelencia del Ministerio y de la Junta de Andalucía. Ha realizado estancias de investigación en universidades de Cagliari, Roma, Ginebra, Buenos Aires, San Luis (Argentina), Guatemala, Florencia (Instituto Europeo), Toulouse e investigación de campo en comunidades indígenas zapatistas de Chiapas. Universidad Pablo de Olavide de Sevilla, España. Espanha. E-mail: mlsorgon@upo.es
} 
espacios mediáticos que ella proyecta (cuarto epígrafe), los factores que explican el éxito mediático de la revolución (quinto epígrafe) y finalmente dos temas más concretos: la función mediática que lleva a cabo el principal protagonista de la revolución, el subcomandante Marcos (sexto epígrafe) y la exitosa estrategia de la indefinición política del zapatismo, que tanto ha contribuido a su aceptación por movimientos y colectivos de diverso signo político (séptimo epígrafe).

El contenido básico del trabajo es el análisis de los espacios y factores mediáticos de la revolución y la valoración de la función mediática del subcomandante Marcos como uno de los principales factores.

La hipótesis central será fijar el valor y alcance mediático de la revolución zapatista y dentro de ella la función mediática desarrollada por el subcomandante Macos, jefe militar y portavoz del Ejército Zapatista de Liberación Nacional (EZLN).

\section{UNA BREVE HISTORIA DE LA REVOLUCIÓN ZAPATISTA DE CHIAPAS}

Unos breves apuntes iniciales para que el lector no versado en la materia conozca los hitos históricos más destacados de la revolución zapatista de Chiapas, que se caracteriza por ser una revolución muy documentada plagada de numerosas fuentes directas. ${ }^{2}$ De estas fuentes se han hecho numerosos elencos o compendios ya desde los inicios de la revolución. ${ }^{3}$ Además de esta extraordinaria documentación, ayudada por la facilidad de la comunicación en internet, la bibliografía sobre la revolución, que gozó de una difusión internacional, es inabarcable. ${ }^{4}$ La revolución se inicia con la rebelión de las comunidades indígenas

\footnotetext{
${ }^{2}$ Las fuentes directas de la revolución zapatista son las sucesivas declaraciones de la Selva Lacandona, irremplazables para conocer las motivaciones, los objetivos y el proceso de la revolución zapatista, así como la Treceava Estela, por las mismas razones. Frecuentemente una nueva Declaración de la Selva Lacandona supone un cambio de rumbo de la revolución. La Sexta Declaración de la Selva Lacandona, la más relevante de las declaraciones, en 2005 comunicó y promovió la apertura de la revolución a otros sectores progresistas iniciando una nueva campaña. Y la Treceava Estela en 2003 dio a conocer la creación de las Juntas de Buen Gobierno, cumbre del desarrollo de la autonomía política zapatista, y el repliegue del ejército zapatista hacia funciones puramente militares, En este conjunto de textos considero de especial importancia un documento que suele pasar desapercibido, el titulado Siete pensamientos en mayo de 2003, porque contiene la filosofía política del subcomandante Marcos, jefe militar del ejército, la persona con seguridad más influyente en la historia de la revolución zapatista. Junto a estos textos básicos el nutrido conjunto de documentos de dos colecciones, la de la editorial Era y la de la editorial Ediciones del Serbal. En la bibliografía figuran los datos completos de estos documentos, a los que remiten las citas de este trabajo

${ }^{3}$ Cito en las referencias bibliográficas al final de este trabajo las compilaciones más importantes al uso.

${ }^{4}$ Es tan abultada la bibliografía, telemática y en papel, acerca de la revolución, que la mejor vía para su conocimiento es acudir a las selecciones temáticas. Bien es verdad que se producen constantes reiteraciones en las publicaciones, muchas de las cuales por otra parte tienen un valor meramente narrativo. Una buena y actualizada selección es: Biblioteca Utopía, $1^{\circ}$ de enero de 2014: a 20 años del levantamiento zapatista, 2014.
} 
chiapanecas el 1 de enero de 1994, bajo la dirección del subcomandante Marcos, jefe militar del Ejército Zapatista de Liberación Nacional (EZLN). Casi coincidiendo con el estallido de la revolución la sociedad civil, mexicana e internacional, de dentro y fuera del territorio mexicano, reclama el diálogo entre los contendientes y como consecuencia se celebran reuniones en la Catedral de San Cristóbal de Las Casas entre representantes del Gobierno mexicano y de las comunidades indígenas zapatistas tras el alto el fuego. Finalmente firman los representantes gubernamentales y los representantes de las comunidades indígenas zapatistas los Acuerdos de San Andrés de 1996, en los que el Gobierno mexicano asume las propuestas indígenas. ${ }^{5}$

El 16 de Febrero de 1996 el EZLN y el Gobierno Federal firmaron los Acuerdos de San Andrés sobre "Derecho y Cultura Indígena". 6 En estos acuerdos se reconoce que "los pueblos indígenas han sido objeto de formas de subordinación, desigualdad y discriminación que les han determinado una situación estructural de pobreza, explotación y exclusión política". También se afirma que "para superar esa realidad se requieren nuevas acciones profundas, sistemáticas, participativas y convergentes de parte del Gobierno y de la sociedad, incluidos, ante todo, los propios pueblos indígenas". Igualmente el Gobierno reconoció que "se requiere la participación de los pueblos indígenas, para que sean actores fundamentales de las decisiones que afectan a su vida, y reafirmen su condición de mexicanos con pleno uso de derechos", por lo tanto "esa nueva relación debe superar la tesis del integracionismo cultural para reconocer a los pueblos indígenas como nuevos sujetos de derecho, en atención a su origen histórico, a sus demandas, a la pluriculturalidad de la nación mexicana y a compromisos internacionales suscritos por el Estado mexicano, en particular el Convenio 169 de la OIT".

Estos Acuerdos también incluyen una reforma de la Constitución con los siguientes reconocimientos: la garantía del ejercicio de los derechos de los pueblos indígenas, el reconocimiento de las comunidades como entidades de Derecho público, el derecho de los municipios con mayoría indígena a asociarse libremente, la garantía de que en las legislaciones de los Estados se establezcan disposiciones para el ejercicio de la autonomía.

\footnotetext{
${ }^{5}$ Para conocer con todo tipo de detalles el proceso negociador entre el Gobierno mexicano y los indígenas zapatistas véase Bernal, A. y Romero A. (1999)

${ }^{6}$ Los Acuerdos de San Andrés constan de un Acuerdo general y tres documentos adicionales. Pueden consultarse en: http://www.nodo50.org/pchiapas/chiapas/documentos/sandres1.htm. (Consulta: $12 / 07 / 2018)$
} 
Comienza a continuación una política gubernamental de silencios, titubeos y engaños, que culmina en la reforma constitucional de 2001, en la que solo en pequeña parte se recogen los Acuerdos de San Andrés dejando fuera las más importantes reivindicaciones de los indígenas zapatistas. ${ }^{7}$ El 15 de marzo de 1998 presentó definitiva e unilateralmente al Consejo de la Unión una iniciativa de reforma constitucional en materia de derechos indígenas, "que se apartaba de lo pactado en San Andrés, contradecía la propuesta de la COCOPA, representaba un obstáculo hacia la consecución de la paz y puso al país al borde de la guerra”. (LÓPEZ BÁRCENAS, 2006, p. 80). "La consecuencia de esto -asegura López Bárcenas (2006, p. 76)- fue que por varios años el debate se centró entre una propuesta legitimada socialmente, que no era iniciativa, y una iniciativa que de aprobarse amenazaba con ser una especie de aborto jurídico", ya que no resolvía las demandas de los directamente involucrados que eran los pueblos indígenas mexicanos.

La reforma constitucional de 2001 no resolvió las demandas de los pueblos indígenas como expresó un comunicado del EZLN y del Congreso Nacional Indígena (CNI) el 1 de Enero de 2001. En los Acuerdos de San Andrés se planteaba la reforma de los artículos 4, 18, 26, 53, 73, 115 y 116 y por el contrario fueron finalmente reformados el 1, 2, 4, 18 y 115.

Con esta reforma se siguen imponiendo las prácticas asistencialistas, impidiendo, por tanto, que las comunidades indígenas puedan definir por ellas mismas su propio desarrollo. En cuanto a los recursos naturales no contempla el acceso, uso y disfrute colectivo, sino que está condicionado por las modalidades de propiedad y tenencia de la tierra, que ampara al latifundio en perjuicio de la propiedad comunal. En cambio se da preferencia a los intereses empresariales. No menciona cómo Me ha parecido oportuno comenzar mi trabajo reseñando los hechos más destacados y los caracteres de la revolución indígena zapatista de Chiapas, porque en el entramado de estos caracteres el lector puede apreciar el valor mediático de esta revolución, denominada por muchos tratadistas como la primera revolución mediática en la que internet desarrolló un gran papel. Tras una breve narración de los hitos más importantes de la revolución y la descripción de sus caracteres (segundo y tercer epígrafe) se pasa a la explicación de los espacios mediáticos que ella proyecta (cuarto epígrafe), los factores que explican el éxito mediático de la revolución (quinto epígrafe) y finalmente dos temas más concretos: la función mediática que lleva a cabo el principal protagonista de la revolución, el

\footnotetext{
${ }^{7}$ I. Arvide ha publicado en una monografía una relación de los errores, abstenciones, hipocresías, silencios del Gobierno mexicano en relación con las reivindicaciones de los zapatistas. El último capítulo, que es un resumen de los anteriores, se titula: "El silencio cae sobre Chiapas" (ARVIDE, 1988, pp. 207-214)
} 
subcomandante Marcos (sexto epígrafe) y la exitosa estrategia de la indefinición política del zapatismo, que tanto ha contribuido a su aceptación por movimientos y colectivos de diverso signo político (séptimo epígrafe).

El contenido básico del trabajo es el análisis de los espacios y factores mediáticos de la revolución y la valoración de la función mediática del subcomandante Marcos como uno de los principales factores.

La hipótesis central será fijar el valor y alcance mediático de la revolución zapatista $y$ dentro de ella la función mediática desarrollada por el subcomandante Macos, jefe militar y portavoz del Ejército Zapatista de Liberación Nacional (EZLN).

Unos breves apuntes iniciales para que el lector no versado en la materia conozca los hitos históricos más destacados de la revolución zapatista de Chiapas, que se caracteriza por ser una revolución muy documentada plagada de numerosas fuentes directas. ${ }^{8}$ De estas fuentes se han hecho numerosos elencos o compendios ya desde los inicios de la revolución. ${ }^{9}$ Además de esta extraordinaria documentación, ayudada por la facilidad de la comunicación en internet, la bibliografía sobre la revolución, que gozó de una difusión internacional, es inabarcable. ${ }^{10} \mathrm{La}$ revolución se inicia con la rebelión de las comunidades indígenas chiapanecas el 1 de enero de 1994, bajo la dirección del subcomandante Marcos, jefe militar del Ejército Zapatista de Liberación Nacional (EZLN). Casi coincidiendo con el estallido de la revolución la sociedad civil, mexicana e internacional, de dentro y fuera del territorio mexicano, reclama el diálogo entre los contendientes y como consecuencia se celebran

\footnotetext{
${ }^{8}$ Las fuentes directas de la revolución zapatista son las sucesivas declaraciones de la Selva Lacandona, irremplazables para conocer las motivaciones, los objetivos y el proceso de la revolución zapatista, así como la Treceava Estela, por las mismas razones. Frecuentemente una nueva Declaración de la Selva Lacandona supone un cambio de rumbo de la revolución. La Sexta Declaración de la Selva Lacandona, la más relevante de las declaraciones, en 2005 comunicó y promovió la apertura de la revolución a otros sectores progresistas iniciando una nueva campaña. Y la Treceava Estela en 2003 dio a conocer la creación de las Juntas de Buen Gobierno, cumbre del desarrollo de la autonomía política zapatista, y el repliegue del ejército zapatista hacia funciones puramente militares, En este conjunto de textos considero de especial importancia un documento que suele pasar desapercibido, el titulado Siete pensamientos en mayo de 2003, porque contiene la filosofía política del subcomandante Marcos, jefe militar del ejército, la persona con seguridad más influyente en la historia de la revolución zapatista. Junto a estos textos básicos el nutrido conjunto de documentos de dos colecciones, la de la editorial Era y la de la editorial Ediciones del Serbal. En la bibliografía figuran los datos completos de estos documentos, a los que remiten las citas de este trabajo

${ }^{9}$ Cito en las referencias bibliográficas al final de este trabajo las compilaciones más importantes al uso.

${ }^{10}$ Es tan abultada la bibliografía, telemática y en papel, acerca de la revolución, que la mejor vía para su conocimiento es acudir a las selecciones temáticas. Bien es verdad que se producen constantes reiteraciones en las publicaciones, muchas de las cuales por otra parte tienen un valor meramente narrativo. Una buena y actualizada selección es: Biblioteca Utopía, $1^{\circ}$ de enero de 2014: a 20 años del levantamiento zapatista, 2014.
} 
reuniones en la Catedral de San Cristóbal de Las Casas entre representantes del Gobierno mexicano y de las comunidades indígenas zapatistas tras el alto el fuego. Finalmente firman los representantes gubernamentales y los representantes de las comunidades indígenas zapatistas los Acuerdos de San Andrés de 1996, en los que el Gobierno mexicano asume las propuestas indígenas. ${ }^{11}$

El 16 de Febrero de 1996 el EZLN y el Gobierno Federal firmaron los Acuerdos de San Andrés sobre "Derecho y Cultura Indígena". ${ }^{12}$ En estos acuerdos se reconoce que "los pueblos indígenas han sido objeto de formas de subordinación, desigualdad y discriminación que les han determinado una situación estructural de pobreza, explotación y exclusión política". También se afirma que "para superar esa realidad se requieren nuevas acciones profundas, sistemáticas, participativas y convergentes de parte del Gobierno y de la sociedad, incluidos, ante todo, los propios pueblos indígenas". Igualmente el Gobierno reconoció que "se requiere la participación de los pueblos indígenas, para que sean actores fundamentales de las decisiones que afectan a su vida, y reafirmen su condición de mexicanos con pleno uso de derechos", por lo tanto "esa nueva relación debe superar la tesis del integracionismo cultural para reconocer a los pueblos indígenas como nuevos sujetos de derecho, en atención a su origen histórico, a sus demandas, a la pluriculturalidad de la nación mexicana y a compromisos internacionales suscritos por el Estado mexicano, en particular el Convenio 169 de la OIT".

Estos Acuerdos también incluyen una reforma de la Constitución con los siguientes reconocimientos: la garantía del ejercicio de los derechos de los pueblos indígenas, el reconocimiento de las comunidades como entidades de Derecho público, el derecho de los municipios con mayoría indígena a asociarse libremente, la garantía de que en las legislaciones de los Estados se establezcan disposiciones para el ejercicio de la autonomía.

Comienza a continuación una política gubernamental de silencios, titubeos y engaños, que culmina en la reforma constitucional de 2001, en la que solo en pequeña parte se recogen los Acuerdos de San Andrés dejando fuera las más importantes reivindicaciones de los indígenas zapatistas. ${ }^{13}$ El 15 de marzo de 1998 presentó definitiva e unilateralmente al

\footnotetext{
${ }^{11}$ Para conocer con todo tipo de detalles el proceso negociador entre el Gobierno mexicano y los indígenas zapatistas véase Bernal, A. y Romero A. (1999)

${ }^{12}$ Los Acuerdos de San Andrés constan de un Acuerdo general y tres documentos adicionales. Pueden consultarse en: http://www.nodo50.org/pchiapas/chiapas/documentos/sandres1.htm. (Consulta: $12 / 07 / 2018)$

${ }^{13}$ I. Arvide ha publicado en una monografía una relación de los errores, abstenciones, hipocresías, silencios
} 
Consejo de la Unión una iniciativa de reforma constitucional en materia de derechos indígenas, "que se apartaba de lo pactado en San Andrés, contradecía la propuesta de la COCOPA, representaba un obstáculo hacia la consecución de la paz y puso al país al borde de la guerra". (LÓPEZ BÁRCENAS, 2006, p. 80). "La consecuencia de esto -asegura López Bárcenas (2006, p. 76)- fue que por varios años el debate se centró entre una propuesta legitimada socialmente, que no era iniciativa, y una iniciativa que de aprobarse amenazaba con ser una especie de aborto jurídico", ya que no resolvía las demandas de los directamente involucrados que eran los pueblos indígenas mexicanos

podrían asociarse y coordinarse los pueblos indígenas como sujetos de derecho público. Se omite la posibilidad de remunicipalización de los territorios en los cuales los pueblos indígenas se encuentran asentados. Tampoco se especifican las transferencias de competencias y funciones, ni las formas de transferencia de recursos económicos.

Finalmente los zapatistas, hartos del cinismo del Gobierno mexicano, a partir de 2003 crean las Juntas de Buen Gobierno -una especie de mancomunidad de municipios- dispersas por el territorio de Chiapas, y comienzan a construir una autonomía política de facto, que llevan a cabo a pesar de las presión y amenazas de militares y paramilitares con la doble política de atraerse a los indígenas más débiles con toda clase de ayudas y de hostigar a los más rebeldes. En efecto, en el año 2003 el EZLN otra vez dio un nuevo impulso a la autonomía indígena. En un comunicado del CCRI-CG, de 19 de julio de 2003, declaró : "Los llamados Acuerdos de San Andrés en Derechos y Cultura Indígena (firmados por el Gobierno Federal y el EZLN el 16 de febrero de 1996 y plasmados en la llamada "Iniciativa de la Ley COCOPA") serán aplicados en territorios rebeldes."14 Y posteriormente anunció el nacimiento de las Juntas de Buen Gobierno, que eran Gobiernos regionales comprendiendo varios municipios autónomos, instauradas el 9 de Agosto de dicho año. En principio se crearon cinco Juntas de Buen Gobierno.

En 2005 hay un importante cambio de la revolución, que se abre a la sociedad civil y a las formaciones políticas y sociales con la finalidad de construir conjuntamente un futuro para México. Es el propósito de la sexta Declaración de la Selva Lacandona. Es el comienzo

del Gobierno mexicano en relación con las reivindicaciones de los zapatistas. El último capítulo, que es un resumen de los anteriores, se titula: "El silencio cae sobre Chiapas" (ARVIDE, 1988, pp. 207-214)

${ }^{14} \mathrm{http}: / /$ www.nodo50.org/pchiapas/chiapas/documentos/19jul.htm (Consulta: 10/08/2018) 
de una nueva fase en la revolución, que abandona su aislamiento y tiende a relacionarse y luchar con colectivos afines.

Posteriormente la revolución y el zapatismo entran en una fase de silencio mediático. El jefe militar Marcos no aparece en público. Comienzan los rumores de su enfermedad, muerte o exilio político. Hasta que en mayo de 2014 con ocasión del asesinato de José Luis Solís, conocido como Galeano, maestro de las bases sociales del zapatismo, Marcos, acompañado de comandantes del EZLN, irrumpe en la explanada del Caracol de La Trinidad, donde se homenajea al asesinado, y anuncia su desaparición y sustitución por el subcomandante insurgente Galeano. Mucho se ha especulado sobre el significado de este anuncio, pero creo que una lectura atenta de su carta de despedida, Entre la luz y las sombras, ${ }^{15}$ aporta las claves del mismo. No hay una sola motivación sino varias en mi opinión. La más importante es el relevo generacional, pues Marcos se congratula de unas juventudes que siguen a pie de lucha incorporando en sus vidas el mensaje de la revolución. ${ }^{16}$ Junto a ella otra justificación reside en la idea más reiterada por Marcos en su carta: Todos somos Marcos y Galeano. La revolución es la obra de un colectivo sin líderes e individualidades. Este sentido colectivo del zapatismo exige la muerte política de Marcos, que según las palabras del subcomandante no es sino "un holograma y una botarga", para que otros, como Galeano, pongan sus nombres a la revolución. ${ }^{17}$ También advierto otra motivación más simple: el natural cansancio de un hombre ya maduro que prefiere dejar paso a otros compañeros con más empuje y quizás más ilusionados.

Como síntesis, en el proceso histórico de la revolución zapatista me atrevo a establecer las siguientes etapas significativas: a) la etapa de la guerra y la negociación con el Gobierno mexicano, b) la etapa de la ruptura con el Gobierno mexicano y la construcción de la autonomía zapatista de facto, c) la etapa de las relaciones con los sectores progresistas de México para emprender conjuntamente una revolución compartida y deliberativa. En la primera etapa la revolución negocia con el enemigo. En la segunda, rompe con el enemigo,

15 http://desinformemonos.org/2014/05/adios-al-subcomandante-marcos-nace-galeano $\quad$ (Consulta: 14.07.2018)

${ }^{16}$ En la carta de despedida citada dice Marcos: "En 3 vueltas nos dimos cuenta de que ya había una generación que podía mirarnos de frente, que podía escucharnos y hablarnos sin esperar guía o liderazgo, ni pretender sumisión ni seguimiento"

${ }^{17}$ En efecto, Marcos vuelve una y otra vez a su idea principal, la misma que ha sostenido en más de 20 años de la revolución: el cambio político desde las bases del pueblo. Y así en su carta de despedida tras anunciar el relevo generacional afirma: "Y el más importante, el relevo de pensamiento: del vanguardismo revolucionario al mandar obedeciendo; de la toma del Poder de Arriba a la creación del poder de abajo; de la política profesional a la política cotidiana, de los líderes a los pueblos; de la marginación de género a la participación directa de las mujeres; de la burla a lo otro, a la celebración de la diferencia" 
que le engaña, y emprende su propio proyecto político de autonomía. En la tercera, la revolución se abre y busca una revolución de todos los sectores progresistas de México y del mundo.

Diría también que la revolución va haciéndose a sí misma en el proceso. No es una revolución con objetivos claros iniciales que hay que conseguir en el proceso revolucionario. Es una revolución que constantemente se está planteando su estrategia y sus objetivos. Y ello es consecuencia de dos factores: a) la política zapatista asamblearia con sumisión del ejército a las decisiones de las asambleas; las asambleas van marcando en el proceso bélico estrategias y objetivos, y b) la conversión de la revolución progresivamente en revolución abierta, compartida y deliberativa con participación de colectivos progresistas mexicanos.

\section{LOS CARACTERES DE LA REVOLUCIÓN ZAPATISTA. EL VALOR MEDIÁTICO DE LA REVOLUCIÓN}

La revolución zapatista es original y se diferencia de otras revoluciones, incluso de las revoluciones latinoamericanas, es decir, de su ámbito territorial. La revolución zapatista chiapaneca es una revolución sui generis, a la que califico con unas notas que la distinguen de otras revoluciones. Ha sido y es una revolución indígena en sus orígenes, nacional en su alcance, con una intensa participación femenina, compartida y deliberativa, pendiente, anónima, alternativa a la guerra civil, mediática y de gran calado estético. Los estudiosos de las revoluciones no han destacado a mi juicio suficientemente la singularidad de la revolución zapatista (perfilada con estas notas puestas en cursiva, las cuales no suelen acompañar a otros procesos revolucionarios).

La revolución zapatista chiapaneca presenta caracteres, que no responden a propósitos de sus actores, sino que se van formando en el proceso de la revolución. Lo que especialmente la singulariza es que, siendo en sus orígenes una revolución indígena, es sin embargo una revolución nacional en sus objetivos y alcance. Una revolución hecha originariamente por los indígenas en favor de todos los mexicanos. El indigenismo va transformando su revolución en una revolución indígena, pero no en una revolución de los indígenas y para los indígenas. Es una revolución nacional, promovida desde los pueblos indígenas, pero a la que pueden sumarse todos los mexicanos, con independencia de su procedencia étnica, pues en favor de todos ellos se hace la revolución. Y de la misma manera que no todos los pueblos 
indígenas participan en la revolución ${ }^{18}$, así también cualquier mexicano no indígena puede sumarse a ella.

Esta idea de la revolución nacional está ya presente desde el principio. Marcos da cuenta de ello al afirmar que los jefes indígenas eran los más exigentes en cuanto a que la primera Declaración de la Selva Lacandona se percibiera como una declaración para toda la nación mexicana y no para el pueblo indígena exclusivamente. Y continúa en las sucesivas declaraciones, pues en la segunda de ellas expresa: "Rechazamos la manipulación y el tratar de desligar nuestras justas demandas de las del pueblo mexicano. Somos mexicanos y no depondremos ni nuestras demandas ni nuestras armas si no son resueltas la Democracia, la Libertad y la Justicia para todos"19. Y el brazo militar de la revolución, el ejército zapatista, también es portador de este sentido nacional de la revolución: "La lucha del EZLN no es sólo para los zapatistas, no es sólo para los chiapanecos, ni sólo para los indígenas. Es para los mexicanos todos" ${ }^{20}$. Los zapatistas siempre se han considerado mexicanos y defendido una autonomía política y un derecho propio dentro -y no fuera- del Estado mexicano. ${ }^{21}$

Otra característica singular es que es una revolución compartida y deliberativa, y que busca la participación de los sectores sociales progresistas, y que en el seno de ellos se debatan y acuerden las estrategias a seguir. También consideran los indígenas que su revolución es una etapa de la revolución permanente. Así como los indígenas de Chiapas resucitan y continúan la inacabada revolución de Emiliano Zapata, así otros les sucederán y recogerán su testigo. Y otra nota distintiva es que es una revolución mediática, cuyo objetivo ha resultado ser la puesta en conocimiento de la sociedad civil de la lamentable situación que atraviesan los indígenas de Chiapas. Y digo que ha resultado ser esta característica, porque probablemente no estaba este propósito en el espíritu de los combatientes indígenas cuando proyectaron e iniciaron la guerra contra el Estado mexicano en enero de 1994, sino que iniciada la guerra les saltó inesperadamente el grito de la sociedad civil, mexicana y del mundo, exigiendo el diálogo y el compromiso de paz. Y entonces el ejército zapatista y las

\footnotetext{
${ }^{18}$ Uno de los primeros comunicados del CCRI-CG va dirigido a “otras organizaciones indígenas" y expresa que los zapatistas respetan las otras formas de lucha de otras organizaciones indígenas. "Nosotros seguiremos respetando a ustedes y respetando sus formas de lucha. Unamos nuestro corazón con la misma esperanza de libertad, democracia y justicia" A otras organizaciones indígenas, Comunicado del CCRI.CG, 20 de enero de 1994 (EDICIONES DEL SERBAL, I, 1994, p. 148)

19 EDICIONES DEL SERBAL, II, 1994, p. 243.

20 EDICIONES DEL SERBAL, I, 1994, p. 171.

${ }^{21}$ Véanse al respecto SORIANO GONZÁLEZ, M.L. (2012, pp. 183-213; 2013, pp. 119-148)
} 
comunidades indígenas hicieron caso a este requerimiento y entablaron conversaciones de paz con el enemigo.

Pero del conjunto de estas notas hay tres que más llaman la atención. Una es la presencia femenina en la vanguardia de las filas del ejército, en la primera línea del combate. Sorprendió a la opinión pública, mexicana y del mundo, que algunas mujeres con alto grado militar estuvieran al frente del EZLN para tomar algunas cabeceras del enemigo en los primeros días de enero de 1994. La presencia femenina en la revolución no es pasiva o testimonial, sino que las mujeres llevan en no pocas ocasiones la voz cantante, esto es, la voz de mando. Las mujeres proponen, critican, dirigen. Están en todos los huecos y lugares del proceso revolucionario; en las bases de apoyo, en la milicia, en la vanguardia combatiente; en las asambleas donde se discute y se toman decisiones y en los encuentros que organizan tanto en el interior como en el exterior de las comunidades. En las escuelas, los centros de saludad, la intendencia. En todas partes. No es concebible la revolución zapatista sin las mujeres. Las mujeres han desempeñado toda clase de tareas en el ejército y en la gobernación, ocupando los puestos de mayor responsabilidad.

La revolución zapatista no solamente eleva la condición de la mujer indígena, sino que la coloca en igualdad de condiciones con el varón. Y esta condición es alcanzada ya en los inicios de la revolución zapatista, lo que dice mucho en su favor. Marcos refiere que antes de la conocida revolución de 1994 hubo una revolución anterior, la de la aprobación de la Ley Revolucionaria de las Mujeres de 1993. Esta ley es aprobada por unanimidad por los jefes indígenas de la Comandancia Clandestina Revolucionaria Indígena (CCRI) a propuesta de una comisión que se había encargado de pasar una encuesta a las mujeres en las comunidades. La Ley Revolucionaria de Mujeres fue aprobada el 8 de marzo de 1993, es decir, bastante antes del estallido de la revolución el 1 de enero de 1994. Fue elaborada y redactada por las mujeres zapatistas y publicada en El Despertador mexicano (1993), medio informativo del EZLN. Las dificultades que tuvieron que atravesar las mujeres zapatistas para conseguir la aprobación de esta prematura ley se narran en uno de los primeros documentos históricos del zapatismo. $^{22}$

Es un hecho bastante significativo que las mujeres, que integraron el EZLN en los momentos de su formación, ya empezaron a exigir sus derechos. Encabezaron en las entrañas del EZLN una rebelión dentro de la rebelión, como viene a decir el subcomandante Marcos.

${ }^{22}$ EDICIONES DEL SERBAL, I, 1994, pp. 156 ss. 
¿Y cuál es la razón de ser de esta temprana revolución de las mujeres? ¿Cómo se explica si las mujeres indígenas no han llegado a tanto en otras revoluciones? ¿Cómo es posible si estas mujeres han ocupado siempre un papel y desempeñado unas funciones por debajo de las de los varones indígenas? La explicación reside en su posición desde el principio del proceso en la vanguardia de la lucha zapatista, y en que llevaron los ideales del zapatismo en el exterior al ámbito interior de sus vidas en las comunidades. No era sociológicamente posible que quienes estaban al frente de la lucha por los derechos y la democracia en el exterior se resignaran a tener una situación de postración y dependencia en el interior. La participación y democratización por las que luchaban tantas mujeres zapatistas en las filas del ejército zapatista no podía corresponder a una ausencia de participación y democratización en las relaciones entre hombres y mujeres zapatistas.

La Ley Revolucionaria de Mujeres podría servir perfectamente como guía en la lucha por sus derechos a mujeres indígenas no zapatistas, tanto en Chiapas como en cualquier lugar del mundo. Aberlardo Hernández Millán manifiesta la mejor opinión posible del papel de las mujeres zapatistas, de las que dice "han llegado a destacar por su vocación igualitaria y su participación combativa; es decir, por el acento puesto en el reconocimiento de sus derechos de género, así como por su lucha por superar esta situación y conseguir un nuevo estatuto". Y añade: "En una sociedad predominantemente machista y racista; esto constituye una referencia ejemplar y un acontecimiento histórico; y no solamente en el cosmos indígena, sino aun en el mundo mestizo". (HERNÁNDEZ, 2007, p. 66)

Frecuentemente los analistas destacan el valor simbólico y referencial de esta ley, por encima de sus limitaciones reales. Quienes se han acercado a ver el alcance social de la ley así lo corroboran. Como botón de muestra Speed, S., Hernández, A., Stephen, L. (2006)

Otra característica a destacar entre las aludidas es su valor deliberativo y compartido. Una revolución consiguientemente de talante generoso, porque es para todos y todos pueden participar. Una revolución -podría decirse- de gran calado democrático. Atención al exacto sentido que se da a la adjetivación "compartida”, pues evidentemente todas las revoluciones desean que se unan a ellas el máximo posible de sectores sociales. Pero no es esto solamente lo que pretende la revolución zapatista, ya que la participación supone el derecho a proponer, debatir y acordar objetivos. Una participación en la deliberación que no suele acontecer en otras revoluciones. 
En 2005 hay un importante cambio de rumbo del movimiento zapatista con ocasión de la publicación de la sexta Declaración de la Selva Lacandona, pues es el comienzo de una nueva etapa en la que el zapatismo salta por encima de su aislamiento y aspira a relacionarse y luchar con colectivos similares: "Queremos luchar-decía la sexta Declaración- junto con todos los que son gente humilde y simple como nosotros y que tienen gran necesidad y que sufren la explotación y los robos de los ricos y sus malos gobiernos aquí en nuestro México y en otros países del mundo" ${ }^{23}$ Un comunicado del CCRI-CG, de 20 de noviembre de 2005 , decía: "En este año de 2005, el EZLN emitió la sexta Declaración de la Selva lacandona con una serie de iniciativas que incluye la de que un grupo de zapatistas del EZLN salga a hacer trabajo político abierto, civil y pacífico, en la llamada “Otra Campaña”. Se abrió así una nueva etapa de la lucha zapatista por la democracia, la libertad y la justicia para México."24

Desde esta fecha comienza una campaña de contactos del zapatismo con otros movimientos y colectivos sociales, que empieza con reuniones en todo el país con la finalidad de una toma de contacto y un conocimiento mutuo de quienes luchan en persecución de los mismo objetivos y de llegar a un programa común de actividades.

¿Por qué este cambio de rumbo del zapatismo? Creo que por la convicción de que solos pueden poco y juntos mucho más. El zapatismo ha sufrido engaños y hostigamientos constantes del Gobierno, que ha sabido aislarle y presentarle ante la sociedad mexicana y mundial como un movimiento extremista y que pretende derechos especiales que rompe el principio de igualdad del Estado de Derecho. Advierte que hay otros colectivos con reivindicaciones iguales o semejantes a las suyas y que una política común del zapatismo y otros movimientos sociales reforzaría la eficacia de su lucha. Este es el objetivo principal a partir de 2005, que da lugar a la última Declaración de la Selva Lacandona: "Porque tal vez unidos con otros sectores sociales que tienen las mismas carencias que nosotros, será posible conseguir lo que necesitamos y merecemos. Un nuevo paso adelante en la lucha indígena sólo es posible si el indígena se junta con obreros, campesinos, estudiantes, maestros, empleados... o sea los trabajadores de la ciudad y el campo". ${ }^{25}$

Esta lucha común se estructura sobre la base de la voluntariedad, sin imposiciones de ninguna clase. El zapatismo no va a decirles a sus socios qué es lo que tienen que hacer. Un adelanto en la lucha contra la explotación capitalista no le da títulos al efecto, ni va a acudir

\footnotetext{
${ }^{23} \mathrm{http} / /$ www.nodo50.org/pchiapas/chiapas/documentos/selva-vi/selva-vi.htm (Consulta: 03/09/2018)

${ }^{24} \mathrm{http}$ ://www.nodo50.org/pchiapas/chiapas/documentos/selva-vi/selvi30.htm (Consulta: 10/09/2018)

${ }^{25} \mathrm{http://www.nodo50.org/pchiapas/chiapas/documentos/selva-vi/selva-vi.htm} \mathrm{(Consulta:10/08/2018)}$
} 
y reunirse donde no es llamado. Todas las partes del movimiento común están en el punto inicial del intercambio y el diálogo y entre todos, en igualdad de condiciones, tienen que construir una política común.

Finalmente la otra característica especialmente sorprendente de la revolución zapatista es su valor mediático, pues en ella están presentes los medios de comunicación desde sus inicios. Los medios van a la revolución y los revolucionarios acuden a los medios. Quizás no parezca esta nota algo singular, pues los medios e internet singularmente están presentes en cualquier movimiento social de crítica o resistencia. Y es verdad, pero falta la proyección histórica de la afirmación. Porque la revolución zapatista comienza el 1 de enero de 1994, cuando internet apenas había hecho acto de presencia en el mundo.

Hago referencia en este trabajo a la revolución zapatista chiapaneca como la primera revolución mediática del mundo y así es, pues surge poco después de la creación de internet. Es vox populi que esta revolución no hubiera tenido tanta repercusión si no hubiera contado con las nuevas tecnologías, que difundían a todo el mundo su existencia y aspiraciones. El sociólogo M. Castells la pone como ejemplo de revolución mediática y punto de referencia de las que le han seguido. "Lo nuevo en la guerra de Chiapas -dice el sociólogo- fue el surgimiento de distintos centros emisores que interpretaron los hechos de forma variadísima. La información pública que llegaba a la sociedad a través de los medios de comunicación y por otras vías alternas que hoy permite la tecnología, fue superior a lo que podían controlar las estrategias de comunicación convencionales". (CASTELLS, 1998, p. 95). También C. Álvarez ha destacado este papel de primera revolución mediática al decir que "la llamada revolución zapatista se ha convertido en un símbolo, en el referente de los movimientos de resistencia contra la globalización, además es, también, el ejemplo al que se suele recurrir para explicar cómo las nuevas tecnologías pueden ser utilizadas por los movimientos de resistencia". ${ }^{26}$

La revolución fue haciéndose mediática, aunque no era ése el propósito de quienes en 1993 sopesaban dar el paso de una declaración de guerra al Estado mexicano. Pronto los rebeldes zapatistas vieron las ventajas para sus intereses del apoyo de la sociedad civil y de los medios de comunicación y desde entonces se fraguó un pacto tácito entre estos medios y

26 Álvarez, C., El movimiento zapatista, una estrategia de comunicación, http://www.uv.es/reguera/representacion/chiapas.htm (Consulta: 21/09/2018) 
los rebeldes. A. Hernández Millán (2007, cap. 5 passim) refiere los encuentros del zapatismo con la sociedad civil y las percepciones que de la misma adquiere el EZLN.

Y así una nota distintiva es que es una revolución mediática, cuyo objetivo ha resultado ser la puesta en conocimiento de la sociedad civil de la lamentable situación que atraviesan los indígenas de Chiapas. O sea, se trata de una característica de la revolución acontecida inesperadamente y que a todos, los profesionales de la información y los zapatistas, les cogió de sorpresa. Desde entonces los zapatistas, con el subcomandante Marcos a la cabeza, buscaron la complicidad de los medios con su causa al advertir que éstos constituían la más sonora caja de resonancia para alcanzar sus objetivos. Se dieron cuenta de que internet era una inesperada herramienta para difundir las aspiraciones de las maltrechas comunidades indígenas a pesar de que larga distancia separara al emisor y al receptivo de los mensajes. En realidad la proximidad física de los simpatizantes con la revolución fue escasa y a cuentagotas, que era compensada con la omnipresente presencia mediática. El mayor contacto se producía de tarde en tarde mediante las caravanas de simpatizantes que llegaban hasta las montañas chiapanecas. Muy espectacular la denominada "Caravana de la Dignidad" de 2001, descrita por La Jornada (2001). Fue habitual en los primeros años de la revolución estas caravanas de simpatizantes. Las páginas que siguen van dedicadas a precisar el alcance del carácter mediático de la revolución zapatista, que por obra de los medios ha pasado de ser una revolución más a convertirse en un movimiento social por encima de las fronteras de los Estados.

\section{LOS ESPACIOS MEDIÁTICOS EN LA REVOLUCIÓN ZAPATISTA.}

Es una revolución mediática telemática, pues las redes internet fueron básicas en su evolución y en el conocimiento de la misma por la opinión pública. En el imaginario de las gentes de muchos países ha quedado la figura del subcomandante Marcos pertrechado de un ordenador colgado del cuello que le acompañaba siempre. Y estamos hablando de 1994, un año después del estreno de las www. Sin lugar a dudas esta revolución hubiera pasado desapercibida como tantas otras revoluciones y rebeliones de los campesinos e indígenas de México, sin la instrumentación propagandística de internet. Podemos señalar tres espacios comunicativos, de menor a mayor, en la cercanía a la revolución que son inversos a la intensidad propagandística desarrollada. El espacio más cercano es el de menor intensidad. Veamos.

1. El primer espacio está representado por los numerosos comunicados de los órganos de la revolución, destacando los 
procedentes de la Comandancia General, órgano supremo del EZLN. En este alto número de comunicados hay que distinguir entre los documentos ordinarios, puntuales y continuados que contenían las decisiones políticas de la marcha de la revolución, y las declaraciones de carácter general, como las seis declaraciones de la Selva Lacandona, de un especial valor porque eran a un tiempo la justificación de los actos revolucionarios, la memoria del proceso revolucionario y la apertura de un nuevo rumbo de la revolución. Una triple función que destaca su valor documental de la revolución, pues a través de estas declaraciones podemos conocer las motivaciones, los hechos y los objetivos revolucionarios. Tales declaraciones tienen una dimensión mediática de primer orden, pues el referente de la sociedad está muy presente en ellos, a la que se alude expresamente con acentos de complicidad y frecuentemente se agradece su colaboración.

2. El segundo espacio está representado por los medios cercanos a la revolución, especialmente radio y prensa, que transmiten los comienzos de la revolución, destacando el periódico La Jornada, que ha seguido siempre el proceso revolucionario y ha publicado sus documentos. ${ }^{27}$ Interesa la lectura de R. Trejo (1994, 382 y ss.), porque desvela la relación de los medios y periodistas con la revolución.

Hubo una primera actitud en estos medios de sorpresa y confusión, que desaparece cuando se dan cuenta de la organización, objetivos y número altísimo de zapatistas participantes y advierten que no se trata de unas simples escaramuzas y pequeñas rebeliones de otros tiempos. Los primeros acercamientos y encuentros son descritos por M. Lavario (1999) en una obra de significativo título, Chiapas: La guerra en papel. Los primeros relatos periodísticos fueron los de los periodistas atrevidos, testigos de los primeros pasos de la revolución, que penetraron en la selva buscando noticias, y los que directamente los revolucionarios, con Marcos en primera fila, transmitieron a los medios. Marcos se dio cuenta muy pronto de la importancia de los medios y que éstos podrían convertirse en sus aliados de la causa revolucionaria, o, si no tanto, al menos en propagandista de la misma, y por ello no esperó a que los medios acudieran a él sino que él mismo les suministró la información que necesitaban. Quizás Marcos no se diera cuenta de esta posible complicidad antes del comienzo de la guerra el 1 de enero de 1994, pero es un hecho evidente que percibió desde el comienzo la importancia de una sociedad civil aliada e informada por los medios.

3. El tercer espacio es el de mayor relevancia, el que hace especialmente mediática a la revolución zapatista, pues está representado por las redes virtuales de la comunicación. Muy pronto la revolución es objeto de atención de numerosas webs, individuales y colectivas, destacando las procedentes de Estados Unidos, México, Italia y España. Este tercer espacio es el más alejado cronológicamente de los orígenes de la revolución, pero sin embargo

27 Véase La Jornada, Chiapas. El alzamiento (1994). La Jornada (periódico y ediciones de documentos y libros) ha seguido el desarrollo de la revolución y ha sido eco de los mensajes de los zapatistas. 
es el más influyente porque su acción alcanza el mayor radio de acción concebible: todo el planeta. Las redes han sido el soporte y el impulso de la revolución a un tiempo, porque se convertían en el depósito de los hechos y decisiones de la revolución y la propagaban y promovían además acciones de apoyo de todo tipo, más o menos intervencionistas. La posición de este nuevo mundo de internet en relación con la revolución diverge pues unas webs y redes se limitan a hacer una labor de proyección a la opinión pública sin más y otras además se ponen del lado de los revolucionarios e intervienen de variada forma en apoyo de los objetivos revolucionarios. Guiomar Rovira (2008) ha descrito este sistema de comunicación y propaganda del zapatismo.

Este tercer espacio mediático del zapatismo se redimensiona al ser incorporado al enorme ámbito de las redes de webs de crítica y resistencia, a las que podemos sintetizar como el espacio virtual del altermundismo o mejor alteractivismo. Las luchas del zapatismo de Chiapas es uno de los puntos clave y más visitados de este ámbito y a través de él se redimensiona y alcanza todos los lugares del planeta. La ambiciosa dimensión mediática del zapatismo acompaña y es producto del alcance temático y geográfico extraordinario y total. El zapatismo sale de su reducido círculo: el de las comunidades indígenas (algunas) de Chiapas y desde ahí, como una bola de nieve va engordando y extendiéndose abarcando un mayor número de sujetos y lugares. La extraordinaria multidimensionalidad del zapatismo es bien expresada por Guiomar Rovira al describir cómo va ganando territorio mediático en su lucha contra el neoliberalimo y la globalización: primero Chiapas; después México; finalmente todo el planeta. $\mathrm{Y}$ en este proceso va aumentando el número y alcance de sus denuncias. "El zapatismo -asegura- aparece desde 1994 interpelando varios niveles de localidad: por un lado, a nivel local enfrenta con las armas a los caciques, a los ganaderos, a los coyotes, pone sobre la mesa el problema de la tierra, la miseria y la violencia estructural... Pero no se limita a eso, el EZLN desafía al estado mexicano, declara la guerra al gobierno y exige "democracia, libertad y justicia". Atenta contra el imaginario colectivo del país y al racismo subyacente en la construcción del estado nación. Tampoco se detienen en este espacio... y los zapatistas enmarcan su lucha en un nivel global contra el neoliberalismo, al que tachan de "sentencia de muerte para los pueblos indígenas." (ROVIRA, 2005, p. 1)

En el ámbito de este tercer espacio comunicativo señalado -el de las webs y redeshay una diversidad de posiciones en la composición de los actores y en la colaboración simpatizante con el zapatismo. Puede afirmarse que con carácter general ha aumentado este espacio en dos de sus elementos: el número de webs y redes y las formas de la colaboración. 
Sagástegui ha realizado un extenso estudio examinando las webs y redes (solo en castellano podemos encontrar más de mil webs) y obtiene como resultados: son los colectivos los que apoyan al zapatismo frente a las escasas webs individuales y dentro de este marco de webs colectivas son las ONGs las que prevalecen en una cifra superior al triple sobre el conjunto de otras organizaciones (políticas, académicas y religiosas). Añade además que la mitad de estas webs no piden acción o intervención en favor de los zapatistas y la otra mitad sí, siendo menos las peticiones de acción individual que la de acción colectiva; acciones colectivas clasificadas como intervenciones asociadas a programas de colectivos o intervenciones conjuntas conectadas a las realizadas por las comunidades indígenas. Muy interesantes las palabras finales del autor: "Los elementos de caracterización del zapatismo on line nos permiten observar que las acciones de apoyo al movimiento han tendido a crecer en cantidad y alcance, si bien se mantienen al margen de las comunidades zapatistas en Chiapas por razones de acceso económico, técnico y cultural”. (SAGÁSTEGUI, 2001, p.12)

\section{LOS FACTORES MEDIÁTICOS EN EL ÉXITO DE LA REVOLUCIÓN ZAPATISTA}

La revolución zapatista desarrolla múltiples conexiones con hechos y acontecimientos que explican su aceptación y propagación en numerosos lugares y colectivos sociales. Señalo algunos hitos importantes en el orden mediático que justifican la rápida propagación y colaboración externa de los revolucionarios zapatistas:

1.- La relación con las reivindicaciones de los indígenas y campesinos pobres mexicanos, especialmente en Chiapas, que conecta con las luchas históricas locales mexicanas. J. González y E. Pólito sitúan las causas de la revolución zapatista -que no es algo nuevo- en los levantamientos anteriores, como la manifestación del 12 de octubre de 1992 que llenó las calles y plazas de San Cristóbal de las Casas. Dicen los autores que 1994 es un año final en uno de los ciclos de las luchas de campesinos e indígenas chiapanecos que se inició en 1985. Un momento importante en este proceso de luchas fue la manifestación de 12 de octubre de 1992 llenando las calles y plazas de San Cristóbal de Las Casas. En 1994 se inicia un nuevo ciclo de una intensidad mayor que la de anteriores levantamientos. (GONZÁLEZ, J., PÓLITO, E., 1995, pp. 101-126).

2.- La relación con los movimientos guerrilleros de América Latina, que conecta con los movimientos de izquierda del mundo. 
3.- El abandono de la lucha por la conquista del poder en México replegándose a exigencias de autogobierno en el marco de un territorio del Estado mexicano, que conecta con las reivindicaciones de las minorías nacionales.

4.- El llamamiento a la creación de un sistema político nuevo desde la base, desde una democracia real, directa y participativa, enfrentada a la falsa democracia del Estado mexicano, que conecta con los movimientos sociales crítico de las democracias formales y deficientes de América Latina y del mundo.

5.- El carácter fuertemente mediático de la revolución zapatista desde sus inicios, que conecta con el surgir de las redes y el hacktivismo. La revolución estalla el 1 de enero de 1994 y se sirve de las recién creadas un año antes herramientas de internet para que sean conocidos sus objetivos en todo el mundo y encontrar el apoyo de la sociedad civil.

6.- Finalmente un factor relevante del éxito de la revolución fue su repercusión en los medios intelectuales, de dentro y fuera de México. Fueron numerosos los intelectuales que apoyaron a la revolución ya desde sus inicios, escribiendo sobre sus valores y objetivos, yendo al escenario de la revolución, incluso entrevistando al subcomandante Marcos. Carlos Fuentes le dedica a la revolución páginas extensas de una publicación de 1994, año de comienzo de la revolución. Poco después escriben sobre ella N. Chomsky, E. Dussel, Díaz Polanco (1997) y otros más en un volumen colectivo de 1997. Al año siguiente, en 1998, G. Quesada y A. L. Pérez Ruiz (1998) compilan textos zapatistas y una serie de opiniones de autores, entre ellos Vargas Llosa y Octavio Paz. Un año después, en 1999, Stavenhagen y González Casanova entran en un interesante debate sobre la revolución en un volumen coordinado por S. Arguedas (1999). Y al año siguiente, en 2000, de nuevo un conjunto de conocidos intelectuales debaten sobre los problemas y alcance de la revolución en otro volumen colectivo al cuidado de C. Aanson y R. Benítez (2000). Este es el sino que persigue a la revolución zapatista, cuyos acentos utópicos e incluso románticos despiertan el interés de los intelectuales de dentro y fuera de México.

En la lista de intelectuales que se hacen eco de la revolución hay relevantes exponentes de América y Europa. En España la repercusión fue intensa como en los demás países europeos. Basta constatar que en el periódico El País escriben artículos Haro Tecglen, Octavio Paz y 
Carlos Fuertes (en la fecha tan temprana como el 9 de enero de 1994 cuando la revolución había comenzado el 1 de enero) y Vargas Llosa (16 de enero de este mismo mes). ${ }^{28}$

\section{EL VALOR MEDIÁTICO DEL SUBCOMANDANTE MARCOS, JEFE MILITAR Y PORTAVOZ DE LA REVOLUCIÓN ZAPATISTA.}

Aunque el subcomandante Marcos repetidas veces ha subrayado que él es un simple vocero del Ejército Zapatista de Liberación Nacional (EZLN), una mera cadena de transmisión de los acuerdos de los órganos del EZLN, el hecho demostrado es que su papel es más significativo en el proceso de la revolución zapatista y en la construcción de su autonomía política. Papel destacado por todos los analistas y biógrafos de Marcos, como Ignacio Ramonet (2001) y Vázquez Montalbán (1999), quienes han dedicado sendos libros a la al significado y alcance de la figura de Marcos.

Tras la lectura de los escritos de Marcos -literarios y propiamente políticos-, de los cuantiosos documentos de la revolución y del desarrollo del proceso revolucionario, creo que podemos distinguir en el principal protagonista de los zapatistas (al menos cara al exterior) cuatro funciones mediáticas:

1.- Su primera función declarada por él mismo con insistencia es la portavocía del EZLN, que él podía desarrollar con solvencia ante las grandes masas de indígenas analfabetos y que a lo sumo conocían su propia lengua indígena pero no el castellano (el castilla, como ellos decían, utilizando una palabra evidentemente muy arcana) Los “castillas" indígenas eran muy pocos en las filas de los zapatistas. Por otro lado, los denominados ladinos de la revolución, es decir, los no indígenas, algunos compañeros de Marcos en las guerrillas de las montañas de la selva Lacandona, eran muy escasos y no tuvieron una proyección mediática en la revolución, quizás porque no disponían de la formación y dotes para la comunicación que ostentaba Marcos.

Marcos es el vocero o portavoz del EZLN. Y como tal depende del máximo órgano del EZLN: el Comité Clandestino Revolucionario Indígena. Hasta los diálogos de la Catedral era sólo jefe militar y desde allí empieza a aparecer como vocero del ejército indígena. "Por mi voz habla la voz del EZLN" comienza con frecuencia Marcos los comunicados de la organización. Por lo tanto, a pesar de firmarlos él, no son producto de él, sino de acuerdos tomados previamente por sus compañeros en comités o consejos. Las posdatas a algunos textos

\footnotetext{
${ }^{28}$ Véase G. Gutiérrez (2004). Con un compendio de artículos del diario sobre la revolución.
} 
oficiales son atribuidas al Subcomandante, que muestra su buen humor e ironía en ellos. Dice Marcos: "Los comunicados deben reflejar el sentimiento de la organización. Eso sí tiene que ser aprobado por los compañeros del Comité. Las cartas y las posdatas sí son mías." ${ }^{29}$ Marcos se refiere al Comité Clandestino Revolucionario Indígena de esta manera: "La dirección son ellos. Ellos me marcan un límite: esto lo puedes decir, esto ya no lo puedes decir (...). Ellos son mis jefes y yo tengo que obedecerlos". 30

En la introducción de las Ediciones de Serbal a entrevistas, cartas y comunicados del EZLN, Marcos da cuenta de cómo se produce la toma de decisiones y redacción de comunicados y normas de la revolución, destacando su escaso papel en el proceso. Ahora bien, el proceso de toma de decisiones no impide que el subcomandante influyera en todo el proceso de la revolución por dos razones, que ni siquiera necesitan ser explicadas al lector. Primera: Marcos gozaba de un gran prestigio en las comunidades indígenas ganado a pulso desde los primeros años de asentamiento de los rebeldes en la selva. Y segunda: era una persona muy instruida frente a las grandes masas de indígenas, en su mayor parte analfabetas, que no hablaban el castellano (el castilla, como ellos decían con una expresión arcana de los tiempos de la conquista de las Indias).

Se mezclan, pues, ambos polos. El subcomandante Marcos y los comandantes indígenas. Basta observar la concomitancia de lo que dice el jefe militar Marcos y lo que dicen los comunicados de la Comandancia General. Se confunde hasta cierto punto Marcos con la Comandancia General y ésta con aquél. No es uno de los comandantes, pero su influencia es enorme. Se trata de influencia y no de identificación. El mismo Marcos asegura que a veces no está de acuerdo con las decisiones de la Comandancia General, v. gr., cuando ésta decidió el comienzo de la guerra al finalizar el año 1993. Pero pienso que la coincidencia es tan grande en general que en los comunicados de la Comandancia se nota la letra y el estilo del subcomandante.

2. La segunda función mediática de Marcos fue la relación comunicativa con la sociedad civil, que en general fue tan importante como el mismo EZLN en el desarrollo de la revolución y el alcance de sus fines. Nos equivocamos si creemos que el proceso revolucionario fue cosa exclusiva del ejército zapatista y las comunidades indígenas zapatistas. Fue la sociedad civil, de México y del mundo, la que impidió que la guerra inicial continuara, exigió el alto el fuego

\footnotetext{
${ }^{29}$ La Jornada, 27 de diciembre de 1995, p 6.

${ }^{30}$ La Jornada, 23 de Febrero de 1994, p. 5. Subcomandante Marcos, Conferencia de prensa.
} 
y de alguna manera obligó al Gobierno mexicano a sentarse en una mesa de negociaciones con los zapatistas. Y los zapatistas, con Marcos a la cabeza, vieron pronto que la sociedad civil era su mejor aliado y la convirtió en la principal destinataria de sus actuaciones y decisiones políticas. A partir de los primeros pasos de la revolución Marcos tuvo siempre a la sociedad civil en su mente a la hora de proponer actuaciones y de ejecutarlas. Fue el punto de relación entre la revolución y la sociedad civil que vio en Marcos a su autorizado interlocutor.

3. La tercera función en el marco mediático es la relación comunicativa con los intelectuales, mexicanos y del mundo, ya que de todos los lugares del planeta surgieron intelectuales interesados por la revolución zapatista y sus objetivos. Difícilmente éstos hubieran podido comprender y apoyar a la revolución zapatista sin la concurrencia y mediación de Marcos, que hablaba el mismo lenguaje que los intelectuales. Los intelectuales trataban a Marcos como un igual, valoraban positivamente sus escritos, que para ellos no tenía un valor político únicamente, sino literario. Marcos fue el cauce por el que los intelectuales llegaron a la revolución, comprendieron el significado, objetivos y alcance de la revolución, y la transmitieron y difundieron en sus respectivos territorios. Si tenemos en cuenta que gran parte de estos intelectuales -Saramago, Ramonet, Chomsky, Kymlicka, etc.- eran puntos de referencia de la opinión pública, nos damos cuenta del gran papel mediático que ellos desarrollaron en la propagación de los ideales de la revolución.

4. Una cuarta función mediática de Marcos fue su aportación literaria al margen de la portavocía de las decisiones políticas del EZLN y la comunicación de los acuerdos de los órganos de la revolución. Sus narraciones, ensayos, cuentos servían de soporte comunicativo de la revolución al ser publicados. Hasta sus cuentos fueron editados para su lectura por niños y niñas. Marcos ha seguido desarrollando su faceta literaria de novelista y ensayista para la que tiene una demostrada vocación, a pesar de los avatares de la revolución. Hasta en Japón, el lejano Japón, se ha apreciado el valor literario de sus escritos.

\section{LA INDEFINICIÓN DEL ZAPATISMO COMO INSTRUMENTO DE ESTRATEGIA MEDIÁTICA.}

Es una cuestión que singulariza a la revolución zapatista: su indefinición que acompaña a sus propósitos de abrirse a todo el mundo de los resistentes a la opresión para construir entre todos, mano a mano, un programa político y de actuaciones consecuentes. El zapatismo surge como respuesta concreta a la situación de miseria y opresión de las comunidades indígenas de Chipas, pero desde ahí va aumentando el radio de su resistencia y 
lucha abarcando al final a todos los colectivos oprimidos del mundo. Su lucha es contra "el neoliberalismo y la globalización" como tantas veces repiten sus documentos, allí donde éstos se encuentren. Una lucha sin fronteras. Es como si todo el mundo fuera un gigantesco pasamontañas, como los que cubren los rostros de los zapatistas chiapanecos, tras los que se ocultan los oprimidos del planeta.

Los zapatistas se declaran como movimiento social de izquierda y proclaman la necesidad de la unión de la izquierda de todo el mundo. Pero poco más. De hecho es un crisol de ideología encontradas, principalmente del marximo de los ladinos que como el subcomandante Marcos se encerraron en la montañas de la selva Lacandona para desde allí iniciar la revolución y de la cosmovisión e ideologías mayas de las comunidades indígenas. En este proceso de encuentro continuado los guerrilleros marxistas fueron siendo atraídos por la forma de pensar y actuar de los indígenas y éstos proporcionaron a aquéllos ingentes masas de combatientes y bases sociales para llevar a cabo sus propósitos revolucionarios. Al final se crea desde ambos polos el EZLN, que no se adhiere a las siglas de ningún partido, ni siquiera tendencia política, y que se afirma como apartidista realizando una crítica durísima de los partidos políticos mexicanos.

¿A qué objetivos responde esta indefinición política del zapatismo? Algunos han indicado que tras ella se oculta una estrategia determinada: la de tener más eco en los medios y conseguir más adeptos. En la medida que no se define consigue que más gentes se adhieran al zapatismo o al menos lo acepten, valoren y propaguen. Yo creo que puede haber otra razón de más peso. La práctica asamblearia indígena es determinante para concebir el escenario político como el lugar en que se discute y se toman las decisiones aceptando las minorías la propuesta de la mayoría. Una práctica asamblearia, la práctica de la verdadera democracia como dicen los zapatistas, es renuente a la adopción de credos políticos determinados. No es casual que esta forma de pensar y actuar, anclada en las tradiciones indígenas, se trasladara a la gran política, a la política de la relación de las comunidades zapatistas con el exterior, y que consecuente con la tradición los zapatistas quisieran hacer un debate político en el entramado con otras comunidades, siendo este debate previo a la toma de posición política determinada. No habría otra posición o ideología que las resultantes del debate y la toma de acuerdos coyunturales. La política diaria se va haciendo con las ideologías triunfantes en cada momento. Esto explica el salto que da la revolución zapatista cuando se inicia "La Otra Campaña", consistente en recorrer todo México para establecer relaciones con otras comunidades y movimientos sociales y tras la discusión llegar a acuerdos y programas para 
una revolución que ya no sería la revolución de los zapatistas, sino la revolución de todos los oprimidos.

Por lo tanto la indefinición del zapatismo obedece a su propio proceso asambleario de debate y toma de decisiones y tiene como resultado la acogida y difusión mediática excepcional de una revolución de los oprimidos sin concretas señas políticas (no, desde luego, señas al uso de los partidos políticos).

\section{CONCLUSIONES.}

1. La revolución zapatista de Chiapas es una revolución original en varios aspectos que se reseñan en el tercer epígrafe de este trabajo, destacando su valor mediático. Es quizás la primera revolución en la que internet como herramienta de conocimiento, propagación y acción tiene un papel muy destacado. Se produjo una convergencia de revolucionarios y agentes de comunicación alrededor de la nueva herramienta telemática. Los primeros acudían a los segundos para llevar la revolución a todos los intersticios posibles de la sociedad civil y los segundos asistían a los primeros comunicando al mundo los hitos y las aspiraciones de la revolución zapatista. Internet ha hecho sin lugar a dudas que una comedida revolución de comunidades indígenas de un Estado de la Federación mexicana se haya convertido en un movimiento social planetario: es ahora la revolución de la sociedad civil mexicana y mundial.

2. La revolución zapatista presenta varios niveles o espacios comunicativos, que van desde los comunicados oficiales de los órganos de la revolución a las webs y redes que se hacen eco de ella y sus objetivos con una doble funcionalidad: como mero instrumento de conocimiento y propaganda y como medio para incentivar la colaboración con las comunidades indígenas zapatistas en diversos grados de participación.

3. Una serie de factores han contribuido al éxito de la revolución zapatista en el ámbito mediático, cada uno de los cuales ha conectado con reivindicaciones, luchas históricas y movimientos sociales ya existentes: luchas locales mexicanas, movimientos críticos con la democracia formal, movimientos nacionalistas y exigentes de autogobierno, movimientos y partidos de izquierda, el altermundismo vía internet.

4. EL jefe militar y portavoz de la revolución zapatista, el subcomandante Marcos, ha desarrollado varias funciones mediáticas conectando la revolución con la sociedad civil mexicana y planetaria. Sin el ejercicio de estas funciones la revolución no sería tan conocida 
ni hubiera despertado tantas simpatías y colaboraciones. Marcos es la pieza fundamental mediática del zapatismo.

5.- Una estrategia exitosa del zapatismo ha sido su indefinición política al estar desprovisto de señas de identidad concretas. Se ha declarado un movimiento de izquierda y que lucha contra "el neoliberalismo y la globalización". Pero nada más. Ha llamado además a otros movimientos sociales a ir juntos para debatir entre todos y definir los programas de actuación. Una revolución compartida, que es otra de las notas singulares de la revolución zapatista. Su indefinición política permite que otros muchos movimientos se le acerquen, máxime cuando se les llama a una colaboración estrecha. Esta estrategia ha sido fundamental en el éxito mediático y aceptación de la revolución.

\title{
FREEDOM OF INFORMATION, MEDIA NETWORKS AND STATE CONTROL. CASE STUDY
}

\begin{abstract}
The aim of this work is to specify the media value of the zapatista revolution in Chiapas' indigenous communities, in the process of conquering seated political autonomy on the basis of an assembly democracy as opposed to a formal and representative democracy of the Mexican State. For this reason the title of the paper responds the media construction of the zapatista democracy. Sections of the project are: a) the description of the character of the cited revolution emphasizing its media value, $b$ ) an explanation of media spaces covering the revolution, c) the causes and factors behind the media success of the revolution, d) media function developed by subcommander Marcos, spokesperson and military leader, and e) the strategy of political indefinition of zapatismo, with the purpose of attracting to its ranks to the greatest number of propagators and partners in the success of the revolutionary goals. The main conclusion is that the lack of ideological definition of zapatismo and the extraordinary role of subcommander Marcos, military leader of the revolution, contributed to the success of the revolution.
\end{abstract}

KEYWORDS: freedom of information, zapatismo, media revolution, internet, indigenous struggles

\section{REFERENCIAS BIBLIOGRÁFICAS}

AANSON, C., BENÍTEZ, R. (coords.), Chiapas. Los desafíos de la paz, México: Porrúa, 
2000

ARGUEDAS, S (coord.), Chiapas en el mundo actual: Diálogo académico en el CRIM, Cuernavaca: UNAM, 1999.

ARVIDE, I. La guerra de los espejos, México: Océano, 1998

BERNAL, A. Y ROMERO A., Chiapas: crónica de una negociación, México: Rayuela, 1999.

BIBLIOTECA UTOPÍA, $1^{o}$ de enero de 2014: a 20 años del levantamiento zapatista, Buenos Aires: Centro Cultural de la Cooperación, 2014.

CASTELLS, M., La era de la información: Economía, Sociedad y Cultura, Volumen 2. El poder de la identidad, Madrid: Alianza, 1998, p. 95

CHOMSKY, N., y otros, Chiapas insurgente, Tafalla: Editorial Txalaparta, 1997.

FUENTES, C., Nuevo Tiempo Mexicano, México: Aguilar, 1994

GONZÁLEZ, J., PÓLITO, E. "Notas para comprender el origen de la rebelión zapatista”, en vol. col. Chiapas, México: UNAM, 1995, pp. 101-126.

GUTIÉRREZ, G., La rebelión zapatista en el diario El País, Guadalajara: Universidad de Guadalajara (Jalisco), 2004.

HERNÁNDEZ MILLÁN, A., EZLN. Revolución para la revolución, Madrid: Editora Popular, 2007.

LA JORNADA, Chiapas. El alzamiento, México: Ediciones La Jornada, 1994

LA JORNADA, La caravana de la dignidad, México, La Jornada Ediciones, 2001.

LAVARIO, M., Chiapas: la guerra en el papel, México: Ediciones Cal y Arena, 1999 
QUESADA, G., PÉREZ RUIZ, A.L., EZLN. La utopía armada. Una visión plural del movimiento zapatista, La Paz: Plural Editorial, 1998.

RAMONET, I., Marcos, la dignidad rebelde, Valencia: Ediciones Cybermonde, 2001

ROVIRA, G. Zapatistas sin fronteras. Las redes de solidaridad con Chiapas y el altermundismo, México: Ediciones Era, 2008.

ROVIRA, G. "El zapatismo y la Red Transnacional”, Razón y Palabra, octubre-noviembre de 2005 , p. 1

htpp://www.razonypalabra-org.mx/anteriores/n47/grovira.html (Consulta: 21/07/2018)

SAGÁSTEGUI, D. Internet: herramienta y espacio de lucha zapatista, Kairos, núm. 8, 2001, p. 12 (www.revistakairos.org/k8-d10.htm) (Consulta: 20/08/2018)

SORIANO GONZÁLEZ, M.L., "El derecho a un sistema jurídico propio y autónomo en los pueblos indígenas de América Latina", Universitas. Revista de Filosofia, Derecho y Política, vol. 16, 2012, pp. 183-213.

SORIANO GONZÁLEZ, M. L., “Organización y filosofía política en la Revolución zapatista de Chiapas", Universitas. Revista de Filosofia, Derecho y Política, vol. 18, 2013, pp. 119148.

SPEED, S., HERNÁNDEZ, A., STEPHEN, L., Dissident Women: Gender and Cultural Politics in Chiapas, Austin: Texas Press, 2006

TREJO, R. Chiapas. La comunicación enmascarada, México: Editorial Diana, 1994.

VÁZQUEZ MONTALBÁN, M., Marcos: el señor de los espejos, Madrid: Aguilar, 1999.

\section{FUENTES DIRECTAS}

ACUERDOS DE SAN ANDRÉS SOBRE "DERECHOS Y CULTURA INDÍGENA" http://www.nodo50.org/pchiapas/chiapas/documentos/sandres1.htm. (Consulta: 12/07/2018) 
EDICIONES DEL SERBAL, Chiapas: la palabra de los armados de verdad y fuego, 2 vols., Barcelona, 1994.

EZLN, El Despertador Mexicano, Órgano Informativo del EZLN, México. 1993.

EZLN, Declaraciones de la Selva Lacando, I-VI, 1993-2005, México, 1993.

EZLN, Documentos y comunicados I-IV, México, Era, 1994-2003.

EZLN, Libertad, democracia y justicia, delirio del EZLN, México, 1996.

SUBCOMANDANTE MARCOS Y LE BOT, YVON, El sueño zapatista, Barcelona: Anagrama, 1997.

SUBCOMANDANTE MARCOS, La Treceava Estela, Julio de 2003.

http://www.nodo50.org(pchiapas/chiapas/documentos/calendas/chiapas2.htm. (Consulta: $12 / 07 / 2018)$

SUBCOMANDANTE MARCOS. Desde las montañas del sureste mexicano, Barcelona: Plaza y Janés, 1999.

Trabalho enviado em 27 de fevereiro de 2019

Aceito em 31 de janeiro de 2020 